\title{
Sexual behaviour and the spread of HIV - Statistical and epidemiological modelling applications
}

\author{
Wim Delva \\ Promotoren: Marleen Temmerman, Stijn Vansteelandt
}

Vakgroep Uro-gynaecologie, Universiteit Gent

Openbare verdediging: 10 mei 2010

De studies die in dit werk worden voorgesteld, richtten zich op verbanden tussen seksueel gedrag en blootstelling aan HIV preventie interventies, alsook op het belang van seksueel gedrag en de structuur van seksuele netwerken voor de verspreiding en preventie van HIV infecties.

In artikels I en 2 pasten we standaard methoden toe voor de statistische analyse van gecorreleerde data, bekomen uit een ondervraging van middelbare schoolstudenten uit de Balkan. De recente geschiedenis van conflict en politieke en socio-economische instabiliteit gaven aanleiding tot onderzoeksvragen omtrent de seksuele gezondheid van de jongeren in deze regio, en hun eventueel beperkte toegang tot seksuele en reproductieve gezondheidszorg.

De studie suggereerde dat de leeftijd waarop jongeren seksueel actief worden en het percentage jongeren dat reeds seksueel actief is in de Balkan niet anders is dan in andere delen van Europa. Bovendien bleek het voorkomen van onveilig seksueel gedrag gelijkaardig te zijn aan de trend die gerapporteerd werden elders in Europa. In onze steekproef hadden $21.1 \%$ van de jongens en $26.6 \%$ van de meisjes geen of een onveilige methode van contraceptie toegepast tijdens hun eerste seksuele contact. Vergelijkbare bevindingen werden gerapporteerd in Zweden, Denemarken en Italië. Lagere percentages, tussen $7 \%$ en ${ }_{12} \%$ werden echter gezien bij jongeren in Zwitserland, het Verenigd Koninkrijk, Frankrijk en Nederland.

Afnemend condoomgebruik naarmate jongeren langer seksueel actief waren, werd niet gecompenseerd door een toename in het gebruik van andere contraceptieve methoden, zoals wel het geval is in sommige West-Europese landen. In onze steekproef gebruiken slechts een kleine minderheid van de seksueel actieve meisjes (van $0 \%$ in Macedonië tot $10.6 \%$ in Bosnië) orale contraceptiva. Gevoelens van schaamte, angst en onzekerheid werden geïdentificeerd als barrières tot het zoeken van advies rond seksualiteit en contraceptieve methoden.

Angst voor de diagnose en voor schending van de privacy, en onwetendheid over plaatsen waar men kan getest worden voor HIV bemoeilijkten volgens de jongeren de toegang tot HIV tests. Slechts $5.9 \%$ van de seksueel actieve middelbare schooljeugd had reeds een HIV test ondergaan, hoewel een HIV test in de medische voorgeschiedenis vaker voorkwam bij jongeren die hoger seksueel risicogedrag vertoonden. Verder had minder dan de helft $(42 \%)$ van de seksueel actieve jongens en meisjes die vermoedden 
dat ze een seksueel overdraagbare infecties hadden opgelopen vervolgens een dokter of gezondheidsdienst bezocht. De belangrijkste redenen om geen medische hulp te zoeken waren het spontaan verdwijnen van de klachten, angst voor de diagnose en schaamte om het probleem te bespreken.

Artikels 3 en 4 handelden over sport als vehikel voor HIV preventie bij jongeren in sub-Sahara Afrika. In artikel 3 stelden we een maatschappelijk kader voor om de determinanten van de effectiviteit van op sport gebaseerde HIV preventieprogramma's te bestuderen. Dit kader werd vervolgens toegelicht aan de hand van voorbeelden en toepassingen uit Zuid-Afrika. HIV preventie interventies met een brede impact op de HIV incidentie vereisen dat de interventies algemeen geaccepteerd worden en ze de doelgroep bereiken, dat ze effectief het seksueel risicogedrag verminderen van personen blootgesteld aan de interventie, en dat ze opereren in een gunstige epidemiologische context.

Artikel 4 onderzoekt de potentiële impact van op sport gebaseerde HIV preventieprogramma's in meer detail aan de hand van de casus van het HIV/AIDS Preventie en Informatie Project van de Mathare Youth Sport Association (MYSA). Dit project is gericht op jongeren in en rond de Mathare Vallei - een sloppenwijk rond Nairobi met een erg hoge HIV prevalentie. In samenwerking met MYSA en onderzoekers aan de Katholieke Universiteit Leuven organiseerden we een cross-sectionele bevraging omtrent het seksuele gedrag en determinanten daarvan bij MYSA leden en een controlegroep van jongeren die geen lid waren van MYSA.

Het onderzoek werd bemoeilijkt door mogelijke vertekening van de resultaten door het potentieel verstorend effect van variabelen zoals leeftijd, geslacht, religie, etniciteit, blootstelling aan media, sociaal kapitaal en opvattingen rond iemands lichaam en gezondheid op het verband tussen MYSA lidmaatschap en indicatoren van seksueel risicogedrag. Gecorrigeerd voor blootstelling aan media - een factor die zowel geassocieerd was aan MYSA lidmaatschap en verhoogd condoomgebruik - bleken MYSA leden nog steeds vaker condooms te gebruiken met hun huidige of laatste partner. Toch bleef het condoomgebruik bij MYSA leden teleurstellend laag: slechts 30.9\% van hen gebruikte een condoom tijdens hun eerste seksuele contact, terwijl $23.2 \%$ consistent condooms zegt te gebruiken met hun laatste/huidige partner.

Gegeven de beperkte financiële middelen en arbeidskrachten voor HIV preventie in sub-Sahara Afrika, dient de geschatte effectiviteit van het MYSA HIV/AIDS Preventie en Informatie Project vergeleken te worden met de effectiviteit van alternatieve HIV preventiemethoden, met het oog op maximale efficiëntie en optimale investering in HIV preventie programma's. We moeten besluiten dat de sociaal gedragsmatige aanpak van HIV preventie zoals die door MYSA is ingevuld moet onderdoen voor het preventiepotentieel van mannenbesnijdenis, microbiciden en frequente HIV testen, in combinatie met vervroegde initiatie van HIV behandeling van geïnfecteerde personen. Het is evenwel mogelijk dat de MYSA interventie ook indirecte effecten op het risico op HIV besmetting had via een vermindering van ongemeten risicofactoren zoals grote leeftijdsverschillen tussen seksuele partners. 
In het laatste deel van dit werk worden epidemiologische modellen ontwikkelend om aspecten van de seksuele netwerkstructuur te bestuderen die mogelijks een sleutelrol vervullen bij de verspreiding van HIV in heteroseksuele populaties in sub-Sahara Afrika. Hoewel verscheidene ecologische studies en bevragingen erop wijzen dat overlappende simultane seksuele relaties een drijvende factor voor HIV epidemieën in vele Afrikaanse landen zijn, oordeelden recente opiniestukken in de literatuur dat de bewijskracht hiervoor beperkt en niet sluitend is.

In artikel 5 werd een wiskundig model opgebouwd op basis van een systeem van gekoppelde partiële differentiaalvergelijkingen om de waarschijnlijke initiële groei van HIV epidemieën in serieel monogame netwerken te bestuderen. We schatten dat de HIV prevalentie in Zuid-Afrika in het begin van de jaren I990 elke 2.9 jaar zou verdubbeld zijn indien HIV enkel via serieel monogame relaties had kunnen overgedragen worden. Minder dan $5 \%$ ( $189 / 4000)$ van de modelsimulaties genereerde verdubbelingstijden tussen 0.7 en I.2 jaar, zoals geobserveerd werd in Zuid-Afrika. Aan de hand van deze 'nul hypothese' benadering, reikten we indirecte argumenten aan voor overlappende relaties als een noodzakelijke faciliterende factor voor de explosieve groei van de HIV epidemieën in Zuid-Afrika en andere landen in zuidelijk Afrika.

Meer directe bewijsvoering voor de sleutelrol van overlappende relaties bij de verspreiding van HIV in sub-Sahara Afrika is echter nodig. Klassieke compartimentmodellen op basis van differentiaalvergelijkingen zijn niet in staat om het volledige effect van overlappende relaties te vatten aangezien deze modellen het vormen en afbreken van relaties tussen individuen niet expliciet simuleren. We ontwikkelden daarom SIMPACT, een nieuw individu-gebaseerd modelleringsinstrument ter simulatie van HIV epidemieën in complexe seksuele netwerken. Artikel 6 beschrijft de hoofdeigenschappen en het onderliggende algoritme van SIMPACT, alsook geplande toepassingen van de software voor dienstverlening aan beleidsmakers, epidemiologische en volksgezondheidskundig onderzoek en de opleiding van epidemiologen en experten in de wiskundige modellering van infectieziekten. SIMPACT gebruikt een gewijzigde 'eerstvolgende reactie' methode om te bepalen welke gebeurtenis eerstvolgend zal plaatsvinden en wat het tijdsinterval tussen deze en de voorgaande gebeurtenis zal zijn. Momenteel kan SIMPACT volgende gebeurtenissen simuleren: het aangaan en afbreken van relaties, HIV overdracht binnen serodiscordante relaties, sterfte ten gevolge van AIDS and andere doodsoorzaken, en geboorte. Een grafische interface laat toe de instantane risicofuncties voor deze gebeurtenissen te wijzigen. Bijkomende hulpinstrumenten maken het bovendien mogelijk de belangrijkste resultaten van de simulaties te visualiseren, zoals de leeftijden van de mannen en vrouwen op het moment van het aangaan van relaties, cross-sectionele en cumulatieve seksuele netwerken en het HIV transmissietraject.

De hierboven vermelde studies dragen bij tot het identificeren van prioriteiten voor interventies en bijkomend onderzoek binnen de seksuele en reproductieve gezondheidszorg voor de studiepopulaties. Artikels I en 2 wijzen op de dringende nood aan effectievere seksuele educatie- en informatie-initiatieven gericht naar jongeren in de Balkan. Dergelijke initiatieven dienen zowel vanuit de school, de media als vanuit jongerenorga- 
nisaties te komen, en moeten rigoureus opgevolgd en geëvalueerd worden. Gelijkaardige conclusies kunnen getrokken worden uit de MYSA studie: gegeven de groeiende interesse in sport voor HIV preventie, is het uitermate belangrijk dat HIV preventie programma's die sport gebruiken als vehikel voor seksuele gedragsveranderingen grondig geëvalueerd worden alvorens de programma's op grote schaal worden aangeboden. De analyse voorgesteld in artikel 5 vormt een eerste stap bij het bestuderen van het belang van seksuele netwerken die niet door seriële monogamie gekenmerkt worden. Verdere studie van seksuele netwerkstructuren en hun relatie met de verspreiding van HIV vergt aanpassingen aan de inhoud van de meeste huidige enquêtes inzake seksueel risicogedrag. SIMPACT, de software toepassing beschreven in artikel 6, werd specifiek ontwikkeld om de verspreiding van HIV in complexe seksuele netwerken te kunnen simuleren. Nieuwe onderzoeksprojecten waarin SIMPACT zal gebruikt worden bij de simulatie van de HIV epidemie in de Kayamandi sloppenwijk nabij Kaapstad starten dit jaar nog. Centraal in deze projecten staat de potentiële impact van vervroegde HIV behandeling op de incidentie van HIV in Zuid-Afrika.

\section{References}

Delva, W., Wuillaume, F., Vansteelandt, S., Claeys, P., Verstraelen, H., Temmerman, M. (2007). Sexual behaviour and contraceptive use among youth in the Balkans. Eur J Contracept Reprod Health Care. 12: 309-316.

Delva, W., Wuillaume, F., Vansteelandt, S., Claeys, P., Verstraelen, H., Vanden Broeck, D., Temmerman, M. (2008). HIV testing and Sexually Transmitted Infection care among sexually active youth in the Balkans. AIDS Patient Care STDS. 22: 817-821.

Delva, W., Temmerman, M. (2006). Determinations of the effectiveness of HIV prevention through sport. In: "Sport and Development" by Vanden Auweele Y, Malcolm C, Meulders B., Leuven: Lannoo Campus, ISBN 978902096593 3, 125-134.

Delva, W., Michielsen, K., Meulders, B., Groeninck, S., Wasonga, E., Ajwang, P., Temmerman, M, Vanreusel, B. (2010). HIV prevention through sport: the case of the Mathare Youth Sport Association in Kenya. AIDS Care. 22: 1012-1020

Delva, W., Pretorius, C., Vansteelandt, S., Temmerman, M., Williams, B. Serial monogamy and the spread of HIV: how explosive can it get?

Delva, W., Vansteelandt., S., Pretorius, C., Hummeling, R., Annemans, L., Temmerman, M. SIMPACT: An individual-based model for HIV epidemics in complex sexual networks. 